\title{
The Effect of Cryo-auriculotherapy on Post-Operative Pain Management following Rotator Cuff Surgery: A Randomized, Placebo-Controlled Study
}

\author{
$* \neq J a c q u e s$ E. Chelly, MD, PhD, MBA; * Steven L. Orebaugh, MD; $\llbracket$ Mark W. Rodosky, MD; \\ $\S$ Yram J. Groff, MD; *Brittany E. Norton, BS; *Amy L. Monroe, MPH, MBA; \\ *David Alimi, MD; *Senthilkumar K. Sadhasivam, MD, MPH, MBA; and *Keith M. Vogt, MD, \\ $\mathrm{PhD}$
}

\section{Authors Affiliations:}

* Department of Anesthesiology and Perioperative Medicine, University of Pittsburgh and UPMC (University of Pittsburgh Medical Center), Pittsburgh, PA, USA

₹ Center for Complementary and Alternative Medicine, Department of Anesthesiology and Perioperative Medicine, Pittsburgh, PA, USA

I Department of Orthopedics, University of Pittsburgh and UPMC, Pittsburgh, PA

$\S$ Groff Orthopaedics, UPMC, Pittsburgh, PA, USA

\section{Corresponding Author:}

Jacques E. Chelly, MD, PhD, MBA

Posner Pain Center, 532 S. Aiken Ave, Suite 407, Pittsburgh, PA 15232

Phone: 412-623-6904; Fax: 412-623-4188

Email: chelje@anes.upmc.edu 


\begin{abstract}
Background: In the context of the current opioid crisis, there is a growing interest in evaluating non-pharmacological solutions to manage post-operative pain. Evidence supports the concept that auriculotherapy may provide significant analgesia
\end{abstract}

Objective: Investigating the efficacy of cryo-auriculotherapy to reduce postoperative opioid consumption following a rotator cuff surgery.

Settings: Academic medical center, USA

Methods: This trial was registered to Clinicaltrials.gov (NCT03860259). A total of 39 subjects undergoing rotator cuff surgery and randomized to receive either an active cryo-auriculotherapy treatment (Auriculotherapy; $n=20$ ) or a placebo treatment (placebo; $n=19$ ) were included in the analysis. For each cryo-auriculotherapy subject, the treatment was performed in the recovery room. The primary endpoint was overall opioid consumption (oral morphine equivalent $=\mathrm{OME}$ ). Secondary endpoints included pain and overall non-narcotic analgesic consumption on postoperative day 5, patient satisfaction and function recovery using the 12-Item Short Form Health Survey (SF-12), time to discharge from the recovery room and the hospital and patient satisfaction, as well as the number of subjects from each group readmitted because of pain-related issues.

Results: The use of cryo-auriculotherapy was associated with a $35 \%$ decrease in total opioid requirement over the first five-day recovery period and a $15 \%$ decrease in pain with movement. Pain with movement in the auriculotherapy group remained lower compared to the placebo group for at least 14 days $(4.47 \pm 2.12$ vs $5.84 \pm 2.39$, respectively; $\mathrm{p}=0.0394)$.

Conclusions: Our data suggests that cryo-auriculotherapy represents an alternative to opioids in patients undergoing rotator-cuff surgery.

\title{
INTRODUCTION
}

The current opioid epidemic has led to a renewed interest in exploring non-pharmacological techniques to treat post-operative pain. ${ }^{(1)}$ Furthermore, the use of opioids is associated with significant adverse effects in the context of surgery, including postoperative nausea and vomiting, respiratory depression, hypotension, immunosuppression, and constipation. (2-5) Although interscalene block is the gold standard for postoperative pain management following shoulder surgery, the duration of the block only covers the initial rehabilitation period, and in most cases, patients require the use of opioids. ${ }^{(6)}$

Auriculotherapy is a non-invasive, complementary technique that has been studied in several surgical models, including tooth extraction, ${ }^{(7,8)}$ hip arthroplasty, ${ }^{(9)}$ gynecologic procedures, ${ }^{(10,}$ 11) and depression. ${ }^{(7,12)}$ All recent reviews have concluded that additional evidence is required to determine the role that such a technique may play in perioperative pain management because there is still a limited number of randomized, placebo-controlled studies ${ }^{(13-16)}$ on its use. Furthermore, several techniques are reported to interact with the ear points included in the proposed treatment, 
including needles ${ }^{(17)}$, lasers $^{(18)}$, magnetic sticking ${ }^{(10)}$, and electrostimulation ${ }^{(19)}$.

The current study was designed to assess the role that auriculotherapy may play in reducing postoperative pain and opioid requirement in opioid-naïve patients undergoing elective primary rotator cuff repair with our standard protocol that includes interscalene block and general anesthesia.

\section{METHODS}

This was a prospective, randomized, placebo-controlled trial conducted at the University of Pittsburgh Medical Center (UPMC) Shadyside and Montefiore hospitals. The protocol was reviewed and approved by the Institutional Review Board (IRB) of the University of Pittsburgh Human Resources Protection Office (STUDY18050099) and was registered to Clinicaltrials.gov (NCT03860259) before any eligible patients were approached and consented.

\section{Recruitment:}

Patients were recruited in the pre-operative holding area of UPMC Shadyside or UPMC Montefiore on the day of their scheduled rotator cuff surgery. Patients who agreed to participate signed an IRB-approved informed consent form and were randomized to receive either an active auriculotherapy treatment (auriculotherapy group) or a placebo auriculotherapy treatment (placebo group) in the recovery room. The randomization sequence was determined using computergenerated random numbers. Each patient was made aware at the time of consent and throughout the study that they could choose to withdraw at any time.

\section{Inclusion Criteria:}

Patients over 18 years of age undergoing elective rotator cuff repair and consented for an interscalene block performed prior to the transfer to the operating room were eligible for study inclusion.

\section{Exclusion Criteria:}

Chronic pain requiring daily opioid use; history of opioid use disorder; contraindications for interscalene block, including allergy to local anesthetics; anatomical malformation that the investigators felt may interfere with performing the nerve block; Raynaud's disease diagnosis, and peripheral vascular disease.

\section{Treatment Groups:}

Auriculotherapy consisted of the treatment of nine ear points. The location of these points was based on cartography developed by Alimi D. ${ }^{(20)}$ These points included $\Omega 2$ (the master point for the mesoderm; A4), the shoulder sensory point (B11), six points involved with the pain pathway at the level of the brainstem and the spine (stellar ganglion (F10); C7, sensory (C11) and motor C7, (CXI), sensory master point (SMP; D17), the reticular master point (RMP, H13), thalamus (G14)), and ACTH (I17).

The auriculotherapy treatment was performed in the recovery room on the ear ipsilateral with the surgery site using a cryoauriculopunctor (Matauris, Maison Alfort, France). The cryoauriculopunctor was comprised of an injector connected to a nitrogen gas canister. Each 
subject was randomized to receive either an active treatment (auriculotherapy group) or an inactive treatment (placebo group). The active auriculotherapy treatment consisted of delivering a $2 \mathrm{~s}$ jet of nitrogen gas at the level of each ear point, whereas the placebo treatment consisted of delivering a $2 \mathrm{~s}$ jet using an empty canister at the level of each point. The cryoauriculopunctor is shown in Figure 1.

\section{Anesthesia and postoperative analgesia:}

Prior to transfer to the operating room, an interscalene block ( $12 \mathrm{ml}$ of bupivacaine $0.5 \%)$ using ultrasound was performed on each subject. The surgery was performed under general anesthesia. Except for the trained research staff who performed the auriculotherapy treatment, the subject, the healthcare team (recovery room nurses, surgeons, members of the acute pain team), and research coordinator collecting data were all blinded to the subject's treatment allocation.

At the time of discharge from the hospital, each subject was given an opioid prescription for five days and instructed to take acetaminophen and ibuprofen for mild to moderate pain and opioids for pain rated as severe (scale: $0-3=$ mild pain; $4-6=$ moderate pain; $7-10=$ severe pain) and instructed to complete and return a diary on postoperative days 1, 2, 3, 4, and 5. Each subject was called on postoperative 14 days, one month, two months, and three months.

\section{Data Collection and Outcome Measures}

Primary outcome: Opioid consumption was collected every day following discharge and is expressed as total opioid consumption from postoperative day 1 to day 5 in oral morphine equivalent (OME in $\mathrm{mg}$ ). Pain scored using a verbal analogue scale (VAS; $0=$ no pain to $10=$ worth possible pain) was also obtained from postoperative days 1 to 3 months. From postoperative day 1 to 5 , pain was expressed as the area under the curve.

Secondary outcome: Time to discharge from the recovery room, time to discharge from the hospital, pain, and opioid consumption on postoperative day 1, 2, 3, 4, and 5 were recorded. In addition, overall non-narcotic analgesic consumption on postoperative day 1 to day 5 , and pain and patient satisfaction related to pain management $(0=$ very dissatisfied to $6=$ very satisfied $)$ on postoperative day $1,2,3,4$, and 5 and 14 days, one month, two months, and three months. Functional recovery was evaluated using the 12-Item Short-Form Health Survey (SF-12) completed prior to surgery and at three months following the surgery. The number of subjects from each group readmitted to the hospital because of pain was also collected.

\section{Statistical Analysis}

Data were analyzed using a modified intend-to-treat analysis. ${ }^{(21)}$ Power analysis accounted for $10 \%$ of subjects not returning their diary as loss of follow up. We estimated that under these conditions, a total of 50 patients would provide $80 \%$ power. A non-paired T-test was performed to determine the significance of the difference between the two groups. $\mathrm{P}<0.1$ was considered significant. Data are expressed as mean \pm standard deviation (SD). 


\section{RESULTS}

A total of 50 subjects signed an informed consent form. Among them, 10 subjects did not return a completed pain diary to report their pain scores and opioid consumption post-operatively. Another subject was excluded because it was found postoperatively that the subject had a history of chronic opioid use (assigned to the placebo group). Consequently, a total of 39 subjects ( 20 subjects in the auriculotherapy group and 19 subjects in the placebo group) were included in the final analysis. Figure 2 presents a flow chart of the subjects who signed informed consent. Table 1 presents the demographic characteristics of subjects included in the final analysis for both groups (age, gender, height, weight, body mass index, and racial distribution). The use of auriculotherapy was associated with a significant $35 \%$ overall reduction in opioid requirement over the five-day study period compared to the placebo treatment: $62 \mathrm{mg} \pm 46 \mathrm{OME} \mathrm{mg}$, vs. $96 \mathrm{mg} \pm 67 \mathrm{OME} \mathrm{mg}$, respectively, $(\mathrm{p}=0.0307)$. This reduction in opioid requirement in the treatment group was associated with a significant $16 \%$ decrease in pain with movement $(21.08 \pm 8.62$ vs $24.97 \pm 11.29$, auriculotherapy vs placebo, respectively; $p=0.0827$ ) but no significant difference in pain at rest ( $15.65 \pm 7.48$ vs $15.47 \pm 9.99$, auriculotherapy vs placebo, respectively; $p=0.4752$ ). Furthermore, after post-operative day one, $20 \%$ of subjects in the active auriculotherapy group versus $11 \%$ in the placebo group didn't use any opioids over the remainder of the five-day study period.

Pain at rest was similar in both groups at the time of discharge from the hospital, $(0.45 \pm 0.76$ auriculotherapy vs $0.89 \pm 1.91$ placebo; $p=0.1707)$ and on the first postoperative day $(5.75 \pm 3.32$ auriculotherapy vs $6.17 \pm 3.01$ placebo; $p=0.3446)$. Pain at rest and during movement progressively decreased in the subjects receiving an active auriculotherapy treatment over the first four days $(3 \pm 2.4$ changes between day 1 vs. day $5 \mathrm{p}=0.0085)$. On day 14 , pain during movement was significantly lower in the auriculotherapy group vs the placebo group $(4.47 \pm 2.12$ in vs 5.84 $\pm 2.39 ; \mathrm{p}=0.0394)$, suggesting a long-lasting analgesic effect of the auriculotherapy. Figure 3 shows pain ratings at rest on postoperative days 14, 30, 60, and 90. Figure 4 shows pain scores with movement on postoperative days 14, 30, 60, and 90 .

No difference between groups was recorded with respect to non-opioid analgesic consumption over the study period (acetaminophen: $4438 \pm 4066$ in the placebo group vs. $5956 \pm 5882$ in the auriculotherapy group, $p=0.1786$; ibuprofen $785 \pm 1577$ in the placebo group vs. $1370 \pm 2386$ in the auriculotherapy group, $\mathrm{p}=0.1858$ ).

No difference between groups was recorded with respect to non-opioid analgesic consumption over the first 5 postoperative days (acetaminophen: $4438 \pm 4066$ in the placebo group vs. $5956 \pm$ 5882 in the auriculotherapy group, $\mathrm{p}=0.1786$; ibuprofen $785 \pm 1577$ in the placebo group vs. 1370 \pm 2386 in the auriculotherapy group, $\mathrm{p}=0.1858)$. No difference between groups was recorded with respect to either discharge time from the recovery room $(67.2 \pm 34.1 \mathrm{~min}$ vs. $59.5 \pm 25.7 \mathrm{~min}$, auriculotherapy vs. placebo group, respectively; $\mathrm{p}=0.2220$ ) or time to discharge from the hospital $(148.0 \pm 47.4 \mathrm{~min}$ vs. $140.1 \pm 32.1 \mathrm{~min}$, auriculotherapy vs. placebo group, respectively; $\mathrm{p}=0.2856)$.

Overall patient satisfaction with pain treatment was found to be similar in both the auriculotherapy and placebo groups, except on day 90 when subjects in the auriculotherapy group reported being more satisfied than those in the placebo group. Table 2 reports the patient satisfaction scores throughout the study period. Lastly, functional recovery assessed with the SF12 was found to be 
similar in both the active and placebo groups over the study period and no subject in either group was reported to be readmitted to the hospital due to pain during the study period.

\section{DISCUSSION}

This randomized, placebo-controlled study demonstrated that the use of auriculotherapy based on Dr. David Alimi's cartography ${ }^{(20)}$ allowed for a $35 \%$ reduction in opioid requirement in opioidnaïve subjects following rotator cuff surgery with a preoperative interscalene block. Since the interscalene block lasts up to 24 hours, it is not surprising that no difference in pain between the two groups was observed on postoperative day 1 . The progressive decrease in pain observed in the auriculotherapy group demonstrated that the optimum effect of auriculotherapy was reached on postoperative day 4. Although, this may represent an argument in favor of performing the auriculotherapy treatment prior to surgery, performing auriculotherapy a few days prior to surgery is not practical because many patients live far away from the hospital.

Dr. Alimi's cartography ${ }^{(20)}$ was initially presented and accepted by the World Federation of Chinese Medicine and presented at the World Congress of Chinese Medicine on September 3, 2011. It is based on the use of a segmentogram using the corpus callosum as its center of symmetry and 189 points on the lateral aspect of the ear and 89 points on the internal aspect of the ear. This nomenclature is side-specific, meaning that the representation of the right ear includes the point of the liver, whereas the left side includes the point of the pancreas. The proposed cartography has been validated by MRI studies, including studies validating the point of the thumb ${ }^{(22,23)}$ and the knee. ${ }^{(24)}$

According to the French school of auriculotherapy led by Alimi, the auriculotherapy treatment is based on the physiopathology of the conditions being treated, meaning that in the case of this study, the points chosen to treat postoperative pain included the master point for the mesoderm (tissue of origin for the musculoskeletal system), the site of the surgery, and points involved in the pain pathway and inflammation. (25) Such an approach is different than the one proposed by Chinese acupuncture, which is based on the use of ear points according to meridians and energy (Yan and Yin). ${ }^{(26)}$

Each ear point corresponds structurally to a Merkel disk, ${ }^{(27)}$ which includes a terminal branch of one of the cranial nerves innervating the ear. Each of these points exists in two states: "physiologic" (characterized by a given difference of potential and the absence of pain) or "pathologic" (characterized by an abnormal difference of potential and the presence of pain) on contact. The status of each point can be established using a galvanometer or by assessing the degree of pain. The terminal nerve branch present at the level of each ear point transmits impulses to the cranial nerve they originate from (the vagal, trigeminal, facial, and glossopharyngeal nerves, or the superficial cervical plexus) ${ }^{(28-29)}$ located at the level of the spine and brainstem. These nuclei interact with ascendant and descendent pathways to "communicate" the central nervous system and the periphery. ${ }^{(30)}$ and interact with a complex network of central nervous system structures including the amygdala, thalamus, and nucleus of tractus solitary. ${ }^{(31-33)}$ The destruction of the nerve terminal of a Merkel disk by an acupuncture needle stimulates the brain to regenerate the disk in its "physiological" according to the third law of D'Otto Khaler, ${ }^{(34)}$ meaning in this case in 
its "physiologic" state and also re-establish the peripheral status of the organ the point represents.

The cryoauriculopunctor we used in this study was developed by Dr. Alimi. ${ }^{(35)}$ It allows for the use of gas instead of needles to interact with the auricular treatment points. Prior studies have shown that in different models, the use of gas produces the same therapeutic response as needle stimulation (Alimi, personal communication). This presents several advantages. First, the use of gas instead of a needle is often better accepted by a patient, especially when they are phobic of needles, and second, it allows for the performance of a true placebo-controlled trial. Thus, in the case of a placebo treatment, the same point is treated using an empty gas canister, resulting in no gas being dispensed. This process gives the patient the impression that a treatment is being administered. When real needles are used and a randomized placebo-controlled trial is performed, the placebo treatment points would consist of placing the needles in "non-active areas of the ear," (17) with the assumption that the points chosen are "non-active." This is a very arbitrary assumption that may explain the fact that a number of randomized, placebo-controlled acupuncture trials are unable to demonstrate a difference between the active and placebo treatments. ${ }^{(9)}$

\section{CONCLUSION}

Cryogenic auriculotherapy, a neurophysiological-based treatment using Dr. Alimi's cartography, was employed as a single treatment just after rotator cuff surgery, during which patients also received an interscalene peripheral nerve block. Using a randomized, placebo-controlled design in this patient population resulted in a reduction in postoperative opioid requirement and reduction in pain with movement for at least 14 days after surgery. Additional studies are needed to further characterize this effect and determine the optimal number and timing of cryogenic auriculotherapy treatments to minimize postoperative pain and opioid use. 


\section{TABLES}

Table 1. Demographics of the Auriculotherapy and placebo groups (subjects included in the final analysis)

\begin{tabular}{|l|c|c|}
\hline & $\begin{array}{c}\text { Auriculotherapy Group } \\
(\mathrm{n}=20)\end{array}$ & $\begin{array}{c}\text { Placebo Group } \\
(\mathrm{n}=19)\end{array}$ \\
\hline Age (years) & $63.2 \pm 9.8$ & $63.6 \pm 7.6$ \\
\hline Gender $(\mathrm{M} / \mathrm{F})$ & $9 / 11$ & $10 / 9$ \\
\hline Height $(\mathrm{cm})$ & $169.3 \pm 10.3$ & $85.0 \pm 14.0$ \\
\hline Weight $(\mathrm{kg})$ & $89.9 \pm 27.1$ & $29.8 \pm 2.6$ \\
\hline BMI $\left(\mathrm{kg} / \mathrm{m}^{2}\right)$ & $31.0 \pm 6.8$ & 0 \\
\hline Race & $19(95 \%)$ & 0 \\
Asian & 0 & $19(100 \%)$ \\
African American & 0 & 0 \\
Caucasian & $1(5 \%)$ & 0 \\
Other & 19.5 & \\
\hline
\end{tabular}

Age (mean $\pm \mathrm{SD}$ ), gender (male/female), height (mean $\pm \mathrm{SD}$ ), weight (mean $\pm \mathrm{SD})$, Body Mass Index (BMI, mean $\pm \mathrm{SD})$ and race distribution (percentages). 
Table 2. Overall patient satisfaction with pain management in the auriculotherapy and placebo group

\begin{tabular}{|l|c|c|c|}
\hline Postoperative period & $\begin{array}{c}\text { Auriculotherapy Group } \\
(\mathrm{n}=20)\end{array}$ & $\begin{array}{c}\text { Placebo Group } \\
(\mathrm{n}=19)\end{array}$ & p-value \\
\hline Day 1 & $4.1 \pm 1.4$ & $4.2 \pm 1.8$ & 0.3749 \\
\hline Day 2 & $4.6 \pm 1.1$ & $4.7 \pm 1.2$ & 0.3862 \\
\hline Day 3 & $4.8 \pm 1.0$ & $5.1 \pm 0.8$ & 0.1735 \\
\hline Day 4 & $4.6 \pm 1.3$ & $4.7 \pm 1.5$ & 0.4304 \\
\hline Day 5 & $4.8 \pm 1.1$ & $4.8 \pm 1.5$ & 0.4902 \\
\hline Day 14 & $5.6 \pm 0.8$ & $5.6 \pm 0.8$ & 0.4371 \\
\hline Day 30 & $5.7 \pm 0.5$ & $5.4 \pm 1.2$ & 0.1950 \\
\hline Day 60 & $5.3 \pm 1.5$ & $5.2 \pm 1.6$ & 0.4124 \\
\hline Day 90 & $5.9 \pm 0.3$ & $4.9 \pm 1.9$ & $0.0268^{*}$ \\
\hline
\end{tabular}

* indicates statistically significant, with $\mathrm{p}<0.1$ 
medRxiv preprint doi: https://doi.org/10.1101/2022.02.05.22270330; this version posted February 6, 2022. The copyright holder for this preprint (which was not certified by peer review) is the author/funder, who has granted medRxiv a license to display the preprint in perpetuity.

\section{It is made available under a CC-BY-NC-ND 4.0 International license .}

\section{FIGURES}

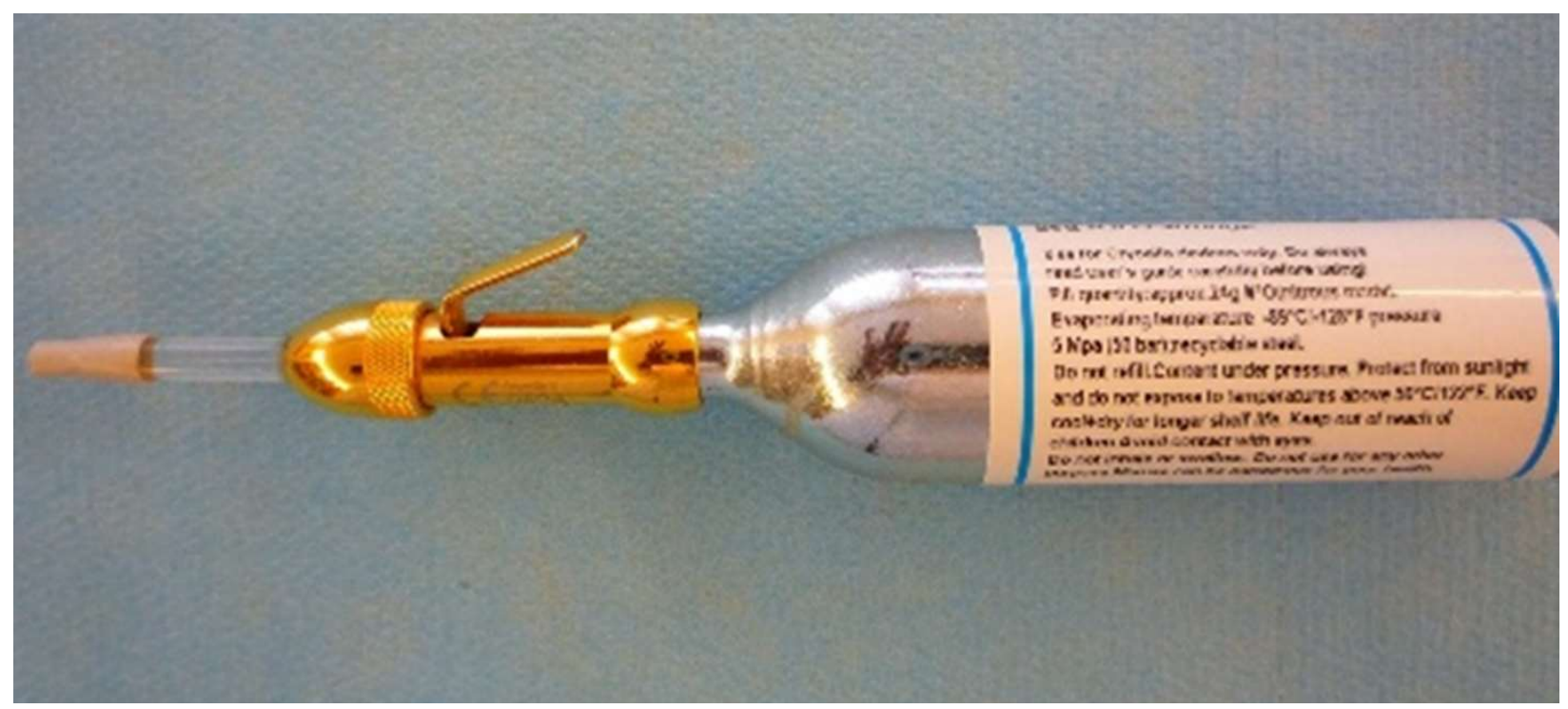

Figure 1. Cryoauriculopunctor composed of one injector connected to a nitrogen canister

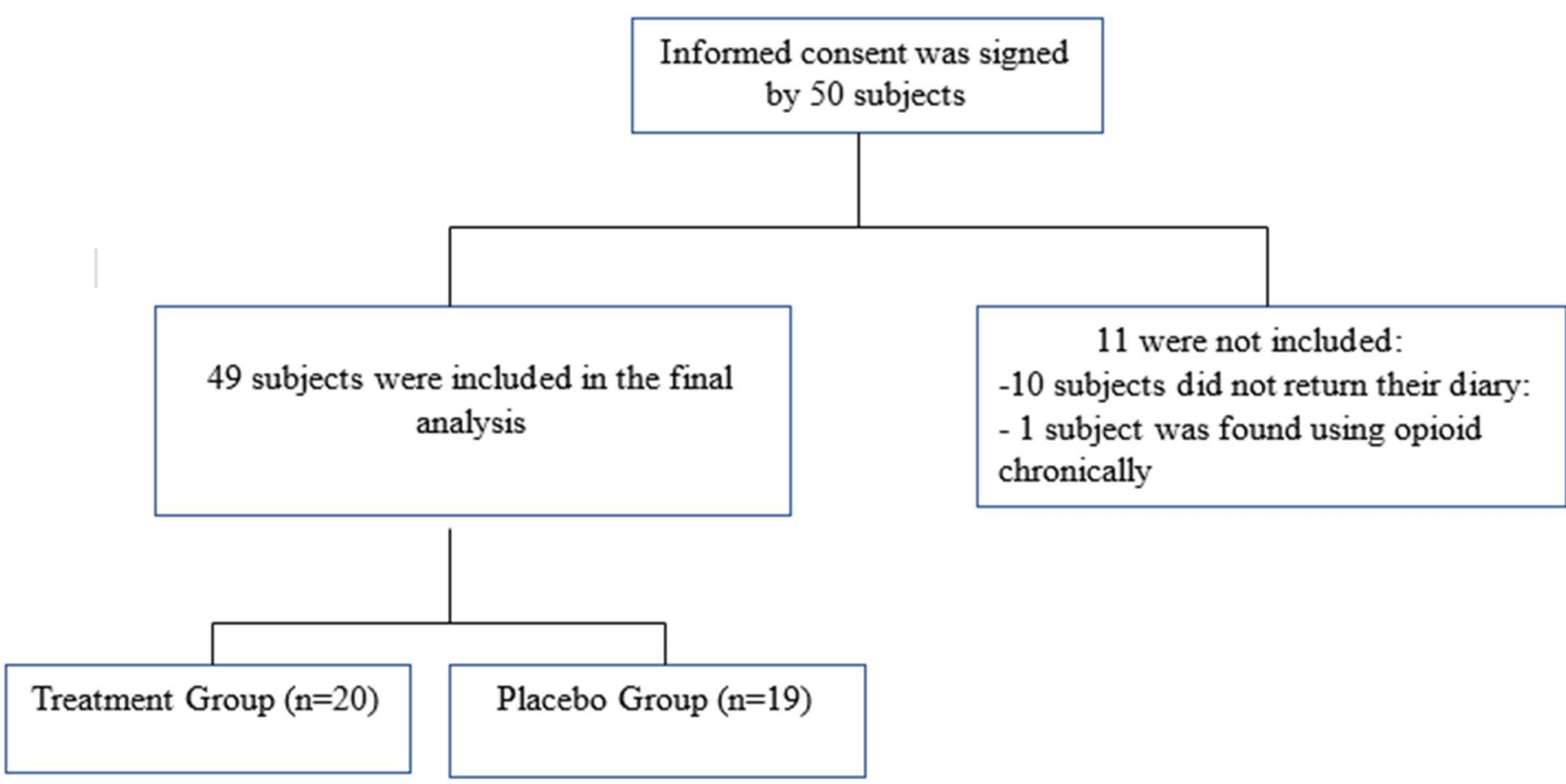

Figure 2. Study flowchart with subjects who were enrolled and included in the final analysis. 
medRxiv preprint doi: https://doi.org/10.1101/2022.02.05.22270330; this version posted February 6, 2022. The copyright holder for this preprint (which was not certified by peer review) is the author/funder, who has granted medRxiv a license to display the preprint in perpetuity.

It is made available under a CC-BY-NC-ND 4.0 International license .

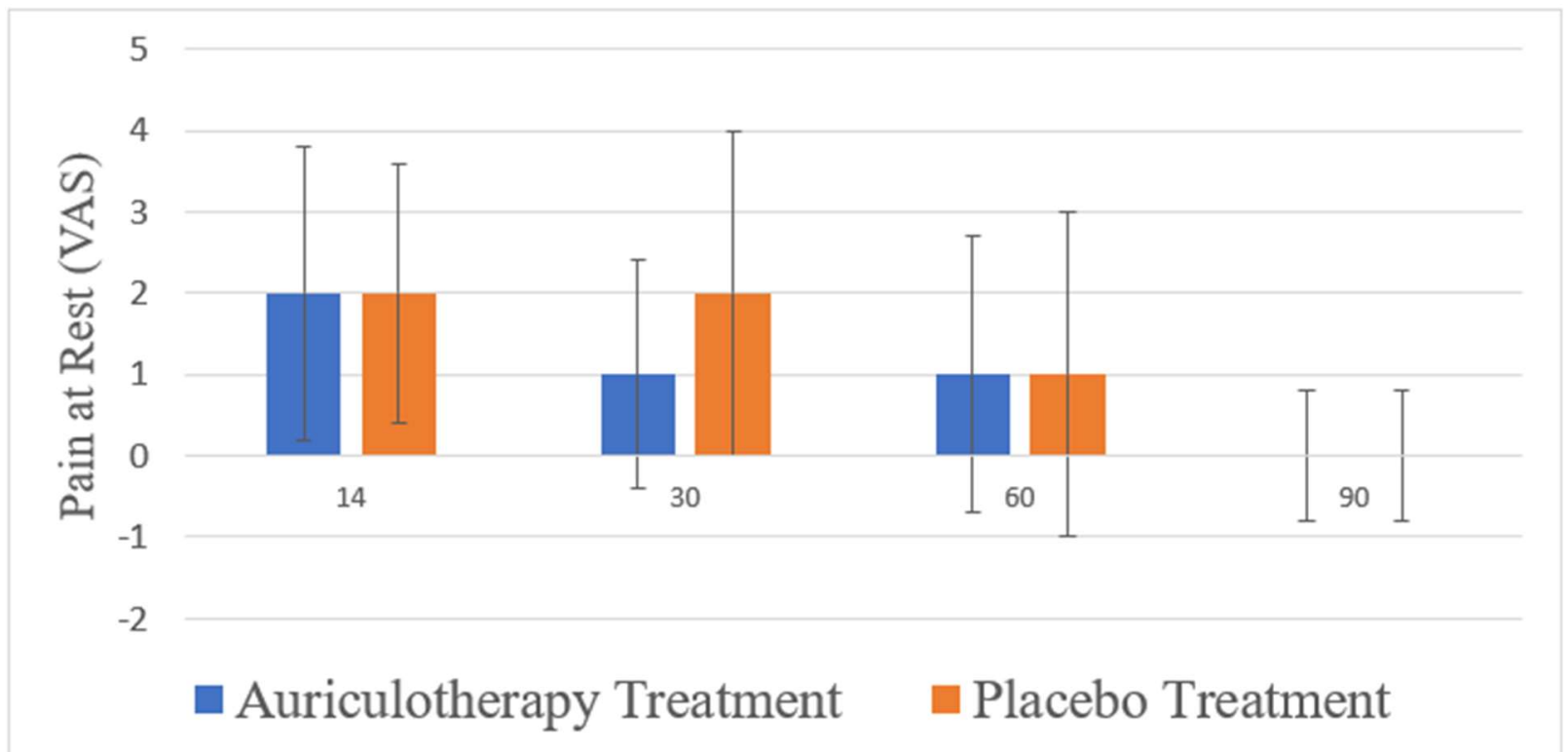

Figure 3. Pain scores on visual analogue scale (VAS) at rest (mean \pm SD) on days 14, 30, 60, and 90 after discharge from the hospital

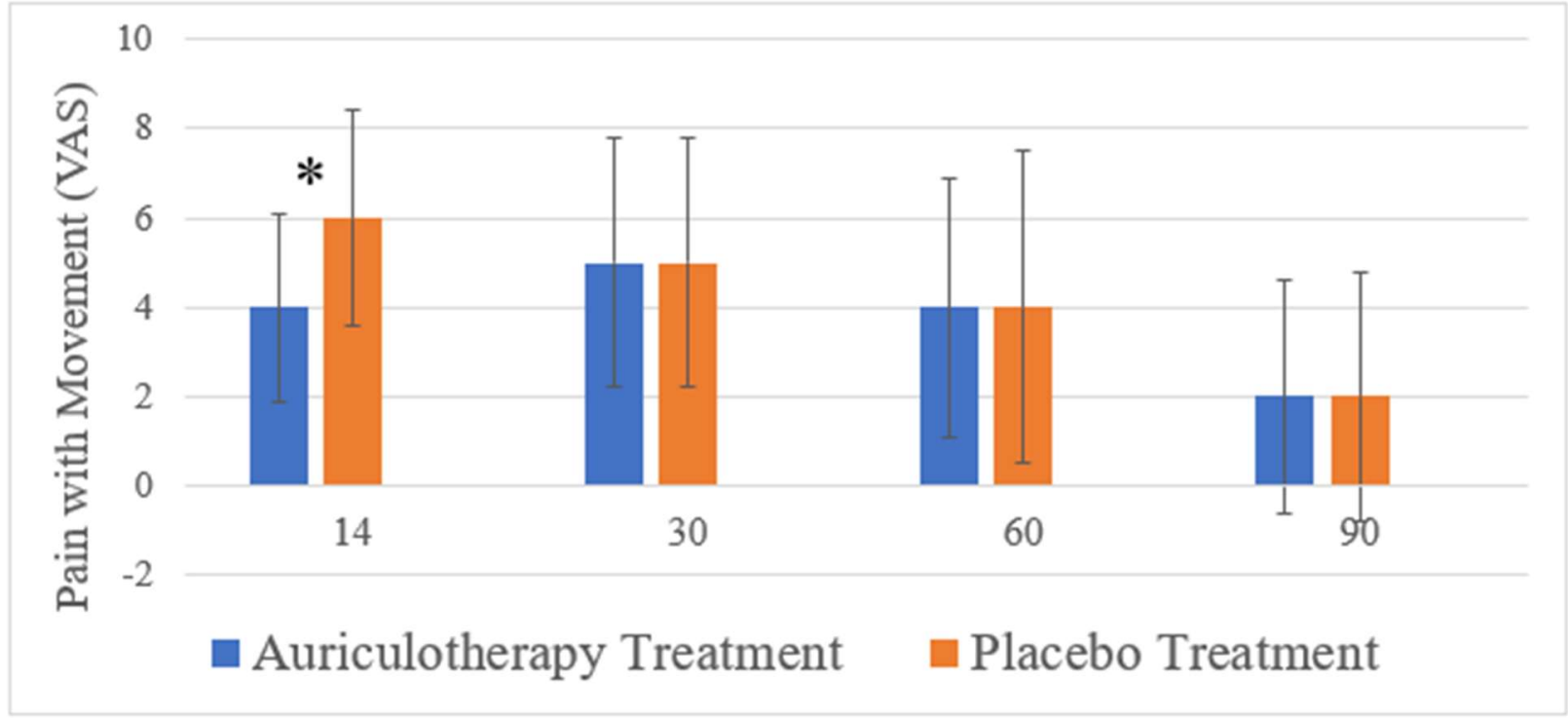

Figure 4. Pain scores on visual analogue scale (VAS) with movement (mean \pm SD) on day 14 (p $=0.0394$ ) and days 30,60, and 90 after discharge from the hospital 
medRxiv preprint doi: https://doi.org/10.1101/2022.02.05.22270330; this version posted February 6, 2022. The copyright holder for this preprint (which was not certified by peer review) is the author/funder, who has granted medRxiv a license to display the preprint in perpetuity.

It is made available under a CC-BY-NC-ND 4.0 International license .

ACKNOWLEDGEMENTS: We want to thank Mrs. Christine Heiner for editing this manuscript.

AUTHOR CONFIRMATION STATEMENT: All named authors meet the International Committee of Medical Journal Editors (ICMJE) criteria for authorship for this article, take responsibility for the integrity of the work as a whole, and have given their approval for this version to be published.

DISCLOSURES: Jacques Chelly, Steven Orebaugh, Mark Rodosky, Yram Groff, Brittany Norton, Amy Monroe, David Alimi, Senthilkumar Sadhasivam, and Keith Vogt declare that they have no conflict of interest.

FUNDING: This study was funded by the Department of Anesthesiology and Perioperative Medicine, University of Pittsburgh, Pittsburgh, PA.

DATA AVAILABILITY: The datasets generated during and/or analyzed during the current study are available from the corresponding author upon reasonable request.

\section{REFERENCES}

1. Brummett CM, Waljee JF, Goesling J, et al. New Persistent Opioid Use After Minor and Major Surgical Procedures in US Adults. JAMA Surg 2017; 152(6): e170504

2. Marino J, Russo J, Herenstein R, et al. Continuous psoas compartment block vs. continuous femoral block or PCA for total hip arthroplasty. J Bone Joint Surg Am. 2009; 91: 29-37

3. Crockett SD, Greer KB, Heidelbaugh JJ, et al. American Gastroenterological Association Institute Guideline on the Medical Management of Opioid-Induced Constipation. Gastroenterology 2019;156: 218-26.

4. Farmer AD, Holt CB, Downes TJ, et al. Pathophysiology, diagnosis, and management of opioid-induced constipation. Lancet Gastroenterol. Hepatol. 2018; 3: 203-12.

5. Kozub E, Uttermark A, Skoog R, et al . Preventing Postoperative Opioid-induced respiratory depression Through Implementation of an Enhanced Monitoring Program. Healthc Qual 2021 Aug 31, doi: 10.1097/JHQ.0000000000000322

6. Warrender WJ, Syed UAM, Hammoud S, et al. Pain Management After Outpatient Shoulder Arthroscopy: A Systematic Review of Randomized Controlled Trials. Am J Sports Med 2017; 45 :1676-86.

7. Karst M, Winterhalter M, Münte S, et al. Auricular Acupuncture for Dental Anxiety: A Randomized Controlled Trial. Anesth. Analg. 2007;104(2):295-300.

8. Lux EA., Wahl G, Erlenwein J, et al. Is supplemental ear acupuncture for surgical tooth removal with local anesthesia effective? A pilot study. Schmerz 2017; 31:489-98. German.

9. Wetzel B, Pavlovic D, Kuse, R, et al. The Effect of Auricular Acupuncture on Fentanyl Requirement During Hip Arthroplasty: A Randomized Controlled Trial. Clin J Pain 2011;27(3):262-267.

10. Li WS, Wan LS, Liu XJ, et al. Effect of Assisted Anesthesia Of Auricular Point Magnetic Sticking On Postoperative Recovery of gynecological Surgery. Zhongguo Zhen Jiu. 2013; 33: 648-52. Chinese.

11. Zhang LH., Cao CL, Li JZ, et al. Influence of Auricular Point Sticking on Incidence of nausea 
medRxiv preprint doi: https://doi.org/10.1101/2022.02.05.22270330; this version posted February 6, 2022. The copyright holder for this preprint (which was not certified by peer review) is the author/funder, who has granted medRxiv a license to display the preprint in perpetuity. It is made available under a CC-BY-NC-ND 4.0 International license .

and vomiting and analgesia effect after gynecological laparoscopy. Zhongguo Zhen Jiu 2013;33:339-41. Chinese.

12. Zhang WF, Sun M, Da LM. Electroacupuncture at Auricular Points for 43 Cases of Postpartum Depression, Zhongguo Zhen Jiu 2012; 32: 1075-6. Chinese.

13. Vieira A, Reis AM, Matos LC, et al. Does auriculotherapy have therapeutic effectiveness? An overview of systematic reviews. Complement Ther Clin Pract. 2018 Nov;33:61-70. doi: 10.1016/j.ctcp.2018.08.005.

14. Baker TE, Chang G. The use of auricular acupuncture in opioid use disorder: A systematic literature review. Am J Addict. 2016 Dec;25(8):592-602. doi: 10.1111/ajad.12453. Epub 2016 Nov 2.

15. Asher GN, Jonas DE, Coeytaux RR, et al. Auriculotherapy for pain management: a systematic review and meta-analysis of randomized controlled trials. J Altern Complement Med 2010 Oct;16(10):1097-108. doi: 10.1089/acm.2009.0451

16. Contim CLV, Santo FHDE, Moretto IG. Applicability of auriculotherapy in cancer patients: an integrative literature review. Rev ESC Enferm USP. 2020 Sep 7;54:e03609. doi: 10.1590/S1980-220X2019001503609

17. Plunkett A, McCoart, A, Howard RS., et al. A Randomized, Single-Blind, Prospective Trial of Auricular 'Battlefield' Acupuncture for The Reduction Of Postoperative Tonsillectomy Pain In Adults. Pain Manag Nurs 2018;8(4):287-295.

18. Wan LS, Li WS, Li WY, et al. Observation on The Anesthesia Effect of General Anesthesia Assisted by Auricular-Laser Therapy In Gynecological Surgery. Zhongguo Zhen Jiu 2013; 33: 237-40. Chinese.

19. Michalek-Sauberer A, Heinzl H, Sator-Katzenschlager SM, et al. Perioperative Auricular Electroacupuncture Has No Effect on Pain and Analgesic Consumption After Third Molar Tooth Extraction. Anesth Analg 2007;104(3):542-547.

20. Alimi D, Chelly JE. New Universal Nomenclature in Auriculotherapy. J Altern Complement Med. 2018;24:7-14.

21. Neuman MD, Feng R, Carson JL, Gaskins LJ, Dillane D, Sessler DI, Sieber F, Magaziner J, Marcantonio ER, Mehta S, Menio D, Ayad S, Stone T, Papp S, Schwenk ES, Elkassabany N, Marshall M, Jaffe JD, Luke C, Sharma B, Azim S, Hymes RA, Chin KJ, Sheppard R, Perlman B, Sappenfield J, Hauck E, Hoeft MA, Giska M, Ranganath Y, Tedore T, Choi S, Li J, Kwofie MK, Nader A, Sanders RD, Allen BFS, Vlassakov K, Kates S, Fleisher LA, Dattilo J, Tierney A, Stephens-Shields AJ, Ellenberg SS; REGAIN Investigators. Spinal Anesthesia or General Anesthesia for Hip Surgery in Older Adults. N Engl J Med. 2021; 385: 2025-35

22. Alimi D, Geisdsmann A, Gardeur D. Auricular acupuncture stimulation measured on functional magnetic Imaging. Med Acup 2002;13:18-21

23. Romoli M, Allais G, Airola G, et al. Ear acupuncture and fMRI: a pilot study for assessing the specificity of auricular points. Neurol Sci. 2014 May;35 Suppl 1:189-93. doi: 10.1007/s10072-014-1768-7.

24. Alimi D, Geisdsmann A, Gardeur D, et al. Study of the stimulation of the auricular areas of the knees French-German and Chinese localization. The Radiology Photon 2014;125:133-41

25. Alimi, D. Chapter V.. Principles, Indications et Strategies Therapeutiques. Practique de l'auriculotherapie. L'Auriculotherapie Medicale: Bases Scientifiques Elsevier Masson SAS, 2017. Pp 103-111. French 
26. Wirz-Ridolfi A. The History of Ear Acupuncture and Ear Cartography: Why Precise Mapping of Auricular Points Is Important. Med Acupunct. 2019 Jun 1;31(3):145-156. doi: 10.1089/acu.2019.1349. Epub 2019 Jun 17

27. Felten DL, Shetty AN. Second edition of the Netter's Atlas of Neuroscience Chapter 9. Peripheral nervous system. Publisher Saunders, Elsevier;2010. pp 135-172

28. Peuker ET, Filler TJ. The nerve supply of the human auricle. Clin Anat 2002;15(1):35-37.

29. Anthwal, N, Thompson H. The Development of The Mammalian Outer and Middle Ear. $J$ Anat 2016;228(2):217-232.

30. Alimi, D L'Auriculotherapie Medicale: Bases Scientifiques, Principles, Indications et Strategies Therapeutiques. Chapitre 11. Synthese neurophysiologic. Practique de 1'auriculotherapie. L'Auriculotherapie Medicale: Bases Scientifiques Elsevier Masson SAS, 2017. pp 69-77. French

31. Rouwette T, Vanelderen P, Roubos, E, et al. The Amygdala, A Relay Station for Switching on And Off Pain. Eur J Pain 2021;16(6):782-792

32. Babygirija R, Sood M, Kannampalli P, et al. Percutaneous Electrical Nerve Field Stimulation Modulates Central Pain Pathways and Attenuates Post-Inflammatory Visceral and Somatic Hyperalgesia in Rats. J Neurosci 2017;356:11-21

33. Mercante B, Ginatempo F, Manca A, Melis F, Enrico P, Deriu F.Med AnatomoPhysiologic Basis for Auricular Stimulation. Med Acupunct. 2018; 30: 141-50

34. Alimi, D. Chapitre 10. Neurophysiologie des perceptions. L'Auriculotherapie Medicale: Bases Scientifiques, Principles, Indications et Strategies Therapeutiques.Elsevier Masson SAS, 2017. Pp 53-66. French

35. Alimi, D. Chapitre 15.Outils therapeutiques. L'Auriculotherapie Medicale: Bases Scientifiques, Principles, Indications et Strategies Therapeutiques.Elsevier Masson SAS, 2017. pp 113-116. French 